\title{
Severe dilatation of the pulmonary artery at the presentation of idiopathic pulmonary hypertension - case report
}

\author{
Authors: Narcisse Nasri ${ }^{1}$, Sara Soraja Nasri ${ }^{1}$, Gordana Pavliša ${ }^{2}$ (mentor) \\ ${ }^{1}$ School of Medicine, University of Zagreb, Zagreb, Croatia \\ ${ }^{2}$ University Hospital Center Zagreb, Department for Respiratory Diseases Jordanovac Zagreb, Zagreb, \\ Croatia
}

DOI: https://doi.org/10.26800/LV-142-supp5-30

\section{Background:}

Idiopathic pulmonary hypertension $(\mathrm{PH})$ is a rare disease defined by the mean artery pulmonary pressure (mPAP) of at least $25 \mathrm{mmHg}$, pulmonary artery wedge pressure $\leq 15 \mathrm{mmHg}$ and a pulmonary vascular resistance $>3$ Wood units in the absence of other causes of precapillary pulmonary hypertension. Pulmonary artery (PA) dilation is a common finding in $\mathrm{PH}$, but only a small proportion of patients with $\mathrm{PH}$ had a diameter $>40 \mathrm{~mm}$. We present a patient with a severe PA dilatation already at the time of diagnosis.

\section{Case report:}

A 63-year-old female was admitted to the hospital to evaluate the cause of PA dilatation visualized on a chest radiograph. The patient complained of shortness of breath for the past three months. The chest CT showed a heavy dilatation of truncus pulmonalis $(59 \mathrm{~cm})$, right and left pulmonary artery $(34 \mathrm{~mm} / 39 \mathrm{~mm})$. Perfusion scintigraphy of the lungs was normal. Echocardiography showed normal morphology and function of the left heart, moderate to severe pulmonary hypertension (RVSP 73 $\mathrm{mmHg}$ ), mild tricuspid regurgitation, dilatation of the right heart and heavy dilatation of truncus pulmonalis (in main diameter $59 \mathrm{~cm}$ ). Right heart catheterization indicatted moderate $\mathrm{PH}$, irreversible to vasodilator agents (mPAP $44 \mathrm{mmHg}$, wedge $13 \mathrm{mmHg}$, PVR $7.09 \mathrm{WU}$ ). Pulmonary function tests, thrombophilia, immunological and infectious analysis were all within the reference values. The patient was diagnosed with idiopathic $\mathrm{PH}$ and treatment with was sildenafil and macitentan was initiated.

\section{Conclusion:}

Only a small proportion of patients with PH have a diameter of main pulmonary artery over $>40 \mathrm{~mm}$. Pulmonary dilatation may predispose the patient to vessel wall rupture, commonly manifested as sudden death. The application of specific vasodilatation therapy may reduce the risk of rupture. It is important to recognize this entity in time and start appropriate treatment. With disease progression, pulmonary artery pressure and the pulmonary vascular resistance gradually increase which can lead to dilation of the proximal pulmonary arteries and right ventricle.

Keywords: idiopathic pulmonary hypertension, pulmonary artery dilatation, truncus pulmonalis 